\title{
Association between the XRCC3 Thr241Met Polymorphism and Breast Cancer Risk: an Updated Meta-analysis of 36 Case- control Studies
}

\author{
Chang-Fei Mao ${ }^{1 \&}$, Wen-Yi Qian ${ }^{2 \&}$, Jian-Zhong Wu ${ }^{1}$, Da-Wei Sun ${ }^{3}$, Jin-Hai Tang ${ }^{1 *}$
}

\begin{abstract}
Background: The X-ray repair cross-complementing group 3 (XRCC3) is a highly suspected candidate gene for cancer susceptibility. Attention has been drawn upon associations of the XRCC3 Thr241Met polymorphism with breast cancer risk. However, the previous published findings remain controversial. Hence, we performed a meta-analysis to accurately evaluate any association between breast cancer and XRCC3 T241M $(23,812$ cases and 25, 349 controls) in different inheritance models. Materials and Methods: PubMed and Web of Science databases were searched systematically until December 31, 2013 to obtain all the records evaluating the association between the XRCC3 Thr241Met polymorphism and breast cancer risk. Crude odds ratios (ORs) together with 95\% confidence intervals (CIs) were used to assess the strength of associations. Results: When all eligible studies were pooled into the meta analysis of XRCC3 T241 M polymorphism, a significantly increased breast cancer risk was observed in heterozygote comparison $(\mathrm{OR}=1.06,95 \% \mathrm{CI}=1.01-1.12)$. No significant associations were found in other models. In subgroup analysis, this polymorphism seemed to be associated with elevated breast risk in Asians. No publication bias was detected.Conclusions: This meta-analysis suggests that the T241M polymorphism confers a weakly increased breast cancer risk. A study with the larger sample size is needed to further evaluate gene-gene and gene-environment interactions of the XRCC3 T241M polymorphism with breast cancer risk.
\end{abstract}

Keywords: XRCC3 - Thr241Met - polymorphism - breast cancer - DNA repair

Asian Pac J Cancer Prev, 15 (16), 6613-6618

\section{Introduction}

Breast cancer is one of the most common cancers among females worldwide so far and is the leading cause of cancer-related mortality for almost $14 \%$ of all cancer deaths (Jemal et al., 2011). It is a heterogeneous disease caused by interactions of environmental and genetic factors. Gage et al. (2012)have confirmed a strong genetic component underlying the etiology of breast cancer. However, to determine which genetic determinants are actually involved in the pathogenesis of breast cancer and the mechanism remain an interpretive challenge.

Growing evidence suggests that DNA damage, caused by UV, ionizing radiation, and environmental chemical agents, can initiate human cancer. DNA Double-strand breaks (DSB) can be produced by exogenous agents such as ionizing radiation. It has been demonstrated that accumulation of unrepaired DSBs can induce cell death and initiate malignancies (Lengauer et al., 1998). Double-strand break repair (DSBR) is the most common form of radiation-induced DNA damage (Ward, 1988) and DNA can be repaired by two pathways-homologous recombination repair (HRR) and non-homologous end- joining (Goode et al., 2002). The XRCC3 (X-ray repair cross-complementing group 3 ) protein is one of protein components involved in the homologous recombination repair (HRR) pathway, responsible for DNA repair. Studies have found the polymorphisms of XRCC3 gene in the population: XRCC3 Thr241Met (C>T, rs861539), 5'-UTR A>G (rs1799794), IVS5-14 A>G (rs1799796) (Breast Cancer Association, 2006).

Growing studies have been conducted to explore the role of XRCC3 Thr241Met on different cancer. Qing-Hua Yin et al. found the polymorphism could act as a head and neck cancer risk factor (Yin et al., 2012). Ling-Yan Qin et al. showed that the XRCC3 Thr241Met polymorphism might not act as a cervical cancer risk factor. However, in subgroup analysis, a significant association was found in Asians under all genetic models (Qin et al., 2013). The association should be studied with a larger, stratified population.

Attention has been also drawn upon the association of Thr241Met with breast cancer risk at a meta-analytical level (Han et al., 2006; Lee et al., 2007; Economopoulos and Sergentanis, 2010; He et al., 2012; He et al., 2013); the most recent meta-analysis on the field has reported

${ }^{1}$ Department of Oncology, Nanjing Medical University Affiliated Jiangsu Cancer Hospital, ${ }^{2}$ Department of Toxicology, School of Public Health, Nanjing Medical University, ${ }^{3}$ Department of Breast Oncology, Affiliated Jiangsu Cancer Hospital, Nanjing University of Chinese Medicine, Nanjing, China*For correspondence: Ifmcfdd@126.com 
that XRCC3 T241M polymorphism is associated with increased cancer risk when all studies were pooled together. But the results remain controversial rather than conclusive. Given the essential role of XRCC3gene in tumorigenesis, we conducted a meta-analysis to evaluate the impact of the XRCC3 Thr241Met polymorphism on susceptibility of breast cancer.

\section{Materials and Methods}

\section{Identification and eligibility of relevant studies}

We performed a comprehensive search of PubMed, Wiley Online Library and Web of Science for relevant articles published with the following keywords : "X-ray repair cross-complementing group 3", "XRCC3", "polymorphisms" or "single nucleotide polymorphism" and "breast neoplasm" or "breast cancer" (last search: December 31, 2013). We also identified additional studies by hand searching references in review articles and original articles. The search was limited to human studies. All eligible studies were retrieved, and their bibliographies were checked for other relevant publications.

\section{Inclusion criteria}

The following criteria were adopted for the included studies: (a) evaluation of the XRCC3 T241M polymorphism and breast cancer risk, (b) independent case-control studies, and (c) provision of sufficient genotype frequencies for both patients and control populations.

\section{Data extraction}

For each eligible publication, the following information was selected independently by two investigators (Mao CF and Qian WY): first author's name, year of publication, source of controls, country, ethnicity, genotype frequencies for cases and controls and the HardyWeinberg equilibrium (HWE) among the controls. The descents of different ethnicity were categorized as Asian, African, and Caucasian. When a study did not declare which ethnic groups were included, or if it was impossible to separate participants according to the phenotype, the study was termed as "mixed population". Disagreement was settled by the discussion of two investigators.

\section{Statistical analysis}

Crude odds ratios (ORs) together with $95 \%$ confidence intervals (CIs) were used to evaluate the strength of association between the XRCC3 polymorphism and breast cancer risk. The pooled ORs were performed for homozygote comparison (MM vs TT), heterozygote comparison (MM vs TM), dominant model (TM+MM vs $\mathrm{TT}$ ), recessive model (TT+TM vs MM), respectively. The Z-test was used to determine the significance of the pooled ORs, and $p$-value $<0.05$ was considered as statistically significant. Subgroup analyses were done by racial descent and source of controls. Between-study heterogeneity was checked by the chi-square-based Q-test (Heterogeneity was considered statistically significant if $p<0.05$ ) (Egger et al., 1997). The fixed-effects model (the Mantel-Haenszel method) was used when there was no heterogeneity among studies (Mantel and Haenszel, 1959); otherwise, the random-effects model (the DerSimonian-Laird method) was applied (DerSimonian and Laird, 1986). Selective bias among the control group was evaluated by the HWE using the chi-square test, and a $p$-value $<0.05$ was considered as significant. Moreover, sensitivity analysis was performed.Begg's funnel plots and Egger's linear regression test were used to assess publication bias (Egger et al., 1997). All analyses were performed using STATA version 11.0 (STATA Corporation, College Station, TX).

\section{Results}

Literature search and meta-analysis databases

Figure 1 illustrated graphically the study flow chart. A total of 26 articles involving 36 eligible studies with 23,812 cases and 25,349 controls were included in the pooled analyses (Jacobsen et al., 2003; Smith et al., 2003a; 2003b; Figueiredo et al., 2004; Forsti et al., 2004; Han et al., 2004; Dufloth et al., 2005; Millikan et al., 2005; Webb et al., 2005; Zhang et al., 2005; Thyagarajan et al., 2006; Breast Cancer Association, 2006; Garcia-Closas et al., 2006; Costa et al., 2007; Sangrajrang et al., 2007; Lee et al., 2007; Loizidou et al., 2008; Smith et al., 2008; Brooks et al., 2008; Krupa et al., 2009; Jara et al., 2010; Santos et al., 2010; Silva et al., 2010; Sterpone et al., 2010; Romanowicz-Makowska et al., 2011; RomanowiczMakowska et al.,2012). Out of the 100 abstracts retrieved through the search criteria, fifty-four were irrelevant, nine articles were excluded because they were conducted on other XRCC3 polymorphisms. Four studies (Bewick et al., 2006; Popanda et al., 2006; Dufloth et al., 2008; Falvo et al., 2011)was excluded given that it has not included controls, seven articles were reviews or meta-analyses. As a result, 26 case-control articles involving 36 studies were included in this meta-analysis. Main characteristics of the included publications investigating the association of XRCC3 T241M polymorphism and breast cancer risk were presented in Table 1.

\section{Meta-analysis results}

As shown in Table.2, significantly increased breast cancer risk was observed in heterozygote comparison $(\mathrm{OR}=1.06,95 \% \mathrm{CI}=1.01-1.12)$ when all studies were pooled in the meta-analysis. However, no significant associations were found for $\mathrm{MM} v s \mathrm{TT}(\mathrm{OR}=1.06$, $\left.95 \% \mathrm{CI}=0.97-1.16, P_{\text {heterogeneity }}=0.003\right), \mathrm{TT} / \mathrm{TM}$ vs $\mathrm{MM}$ $\left(\mathrm{OR}=0.93,95 \% \mathrm{CI}=0.87-1.01, P_{\text {heterogeneity }}=0.008\right), \mathrm{TM} / \mathrm{MM}$ $v s$ TT $\left(\mathrm{OR}=1.02,95 \% \mathrm{CI}=0.96-1.07, P_{\text {heterogeneity }}=0.017\right)$. Interestingly enough, in the subgroup analysis by ethnicity, significantly increased risks were found among Asians (TM/MM vs TT: $\mathrm{OR}=1.34,95 \% \mathrm{CI}=1.09-1.64$, $\left.P_{\text {heterogeneity }}=0.819\right)$ and Mixed ethnicities (MM vs TM: $\mathrm{OR}=1.18,95 \% \mathrm{CI}=1.02-1.35, P_{\text {heterogeneity }}=0.215 ; \mathrm{TT} / \mathrm{TM}$ vs MM: OR=0.87, 95\% CI $\left.=0.76-0.99, P_{\text {heterogeneity }}=0.137\right)$. When stratified by source of controls, We also found that there was a statistically significant link between the XRCC3 T241M polymorphism and breast cancer risk in population-based studies (MM vs TT: $\mathrm{OR}=1.10$, $95 \% \mathrm{CI}=1.03-1.18, P_{\text {heterogeneity }}=0.246 ; \mathrm{MM}$ vs TM: $\mathrm{OR}=1.10,95 \% \mathrm{CI}=1.03-1.18, P_{\text {heterogeneity }}=0.520 ; \mathrm{TT} / \mathrm{TM}$ 
DOI:http://dx.doi.org/10.7314/APJCP.2014.15.16.6613

The XRCC3 Thr241Met Polymorphism and Breast Cancer Risk: an Updated Meta-analysis

Table 1. General Characteristics of Studies Included in the Meta-Analysis

\begin{tabular}{|c|c|c|c|c|c|c|c|c|c|c|c|}
\hline \multirow[t]{2}{*}{ First author } & \multirow[t]{2}{*}{ Year } & \multirow[t]{2}{*}{ SOC } & \multirow[t]{2}{*}{ Country } & \multirow[t]{2}{*}{ Ethnicity } & \multicolumn{3}{|c|}{ Case } & \multicolumn{3}{|c|}{ Control } & \multirow[t]{2}{*}{ HWE } \\
\hline & & & & & TT & $\mathrm{TM}$ & MM & TT & TM & MM & \\
\hline Smith TR & 2003 & $\mathrm{HB}$ & USA & Caucasian & 96 & 105 & 51 & 104 & 129 & 35 & 0.611 \\
\hline Jacobsen & 2003 & PB & Denmark & Caucasian & 163 & 203 & 59 & 160 & 198 & 65 & 0.772 \\
\hline Smith TR & 2003 & PB & USA & Caucasian & 62 & 74 & 26 & 112 & 141 & 49 & 0.680 \\
\hline Han & 2004 & PB & USA & Mixed & 388 & 429 & 135 & 468 & 607 & 170 & 0.225 \\
\hline Figueiredo & 2004 & PB & Canada & Caucasian & 139 & 186 & 77 & 146 & 200 & 56 & 0.341 \\
\hline Forsti & 2004 & PB & Finland & Caucasian & 111 & 80 & 32 & 161 & 110 & 27 & 0.198 \\
\hline Forsti & 2004 & PB & Poland & Caucasian & 72 & 85 & 15 & 89 & 88 & 25 & 0.654 \\
\hline Dufloth & 2005 & $\mathrm{HB}$ & Brazil & Mixed & 88 & 57 & 29 & 68 & 35 & 15 & 0.005 \\
\hline Millikan & 2005 & PB & USA & Caucasian & 505 & 578 & 171 & 435 & 555 & 142 & 0.086 \\
\hline Millikan & 2005 & PB & USA & African & 482 & 222 & 41 & 421 & 211 & 44 & 0.015 \\
\hline Zhang & 2005 & $\mathrm{HB}$ & China & Asian & 107 & 80 & 33 & 166 & 115 & 29 & 0.170 \\
\hline Webb & 2005 & $\mathrm{~PB}$ & Australia & Mixed & 91 & 44 & 14 & 59 & 54 & 15 & 0.625 \\
\hline Webb & 2005 & PB & Australia & Caucasian & 500 & 612 & 184 & 248 & 321 & 91 & 0.425 \\
\hline Thyagarajan & 2006 & $\mathrm{HB}$ & USA & Caucasian & 160 & 192 & 67 & 126 & 157 & 40 & 0.405 \\
\hline BCAC HBBCS & 2006 & $\mathrm{HB}$ & Germany & Caucasian & 95 & 119 & 42 & 77 & 88 & 29 & 0.640 \\
\hline BCAC Madrid & 2006 & $\mathrm{HB}$ & Spain & Caucasian & 255 & 274 & 92 & 281 & 287 & 105 & 0.028 \\
\hline BCAC SEARCH & 2006 & $\mathrm{~PB}$ & UK & Caucasian & 1177 & 1462 & 465 & 1607 & 1898 & 549 & 0.760 \\
\hline BCAC Seoul & 2006 & $\mathrm{HB}$ & Korea & Asian & 502 & 53 & 1 & 355 & 31 & 0 & 0.411 \\
\hline BCAC Sheffield & 2006 & $\mathrm{HB}$ & UK & Caucasian & 458 & 555 & 168 & 437 & 534 & 195 & 0.144 \\
\hline BCAC USRTS & 2006 & PB & USA & Caucasian & 281 & 336 & 98 & 402 & 480 & 155 & 0.550 \\
\hline Garcia-Closas & 2006 & $\mathrm{~PB}$ & USA & Caucasian & 1102 & 1419 & 457 & 973 & 1213 & 368 & 0.748 \\
\hline Garcia-Closas & 2006 & PB & Poland & Caucasian & 785 & 907 & 282 & 980 & 1039 & 266 & 0.709 \\
\hline Costa & 2007 & $\mathrm{HB}$ & Portugal & Caucasian & 108 & 106 & 43 & 346 & 201 & 95 & 0.000 \\
\hline Sangrajrang & 2007 & $\mathrm{HB}$ & Thai & Asian & 437 & 69 & 1 & 384 & 38 & 2 & 0.322 \\
\hline Lee & 2007 & $\mathrm{HB}$ & Korean & Asian & 437 & 51 & 1 & 349 & 29 & 0 & 0.438 \\
\hline Loizidou & 2008 & PB & Cyprus & Mixed & 312 & 560 & 220 & 351 & 600 & 226 & 0.285 \\
\hline Smith TR & 2008 & $\mathrm{HB}$ & USA & Caucasian & 124 & 137 & 54 & 158 & 184 & 59 & 0.649 \\
\hline Smith TR & 2008 & $\mathrm{HB}$ & USA & African & 32 & 19 & 1 & 48 & 20 & 5 & 0.169 \\
\hline Brooks & 2008 & PB & USA & Mixed & 254 & 259 & 98 & 249 & 286 & 76 & 0.661 \\
\hline Krupa & 2009 & $\mathrm{HB}$ & Poland & Caucasian & 29 & 68 & 38 & 29 & 107 & 39 & 0.003 \\
\hline Silva & 2010 & $\mathrm{HB}$ & Portugal & Caucasian & 109 & 138 & 42 & 178 & 276 & 94 & 0.460 \\
\hline Santos & 2010 & $\mathrm{HB}$ & Brazil & Mixed & 28 & 31 & 6 & 49 & 29 & 7 & 0.370 \\
\hline Jara & 2010 & $\mathrm{HB}$ & Chilean & Mixed & 149 & 91 & 27 & 296 & 182 & 22 & 0.366 \\
\hline Sterpone & 2010 & $\mathrm{HB}$ & Italy & Caucasian & 18 & 21 & 4 & 14 & 14 & 3 & 0.853 \\
\hline Romanowicz-Makowska & 2011 & $\mathrm{HB}$ & Poland & Caucasian & 190 & 348 & 162 & 158 & 354 & 196 & 0.939 \\
\hline Romanowicz-Makowska & 2012 & $\mathrm{HB}$ & Poland & Caucasian & 210 & 370 & 180 & 178 & 366 & 216 & 0.343 \\
\hline
\end{tabular}

SOC: source of controls; PB:Population-based; HB:Hospital-based; HWE:Hardy-Weinberg equilibrium

Table 2. Meta-Analysis of the XRCC3 Thr241Met Polymorphism on Breast Cancer

\begin{tabular}{|c|c|c|c|c|c|c|c|c|c|}
\hline Variables & $\begin{array}{c}\mathrm{N} \text { of } \\
\text { studies }\end{array}$ & $\begin{array}{c}\text { MM vs TT } \\
\text { OR }(95 \% \mathrm{CI})\end{array}$ & $\mathrm{p}^{\mathrm{b}}$ & $\begin{array}{c}\text { MM vs TM } \\
\text { OR }(95 \% \mathrm{CI})\end{array}$ & $\mathrm{p}^{\mathrm{b}}$ & $\begin{array}{c}\text { TT/TM vs MM } \\
\text { (recessive) } \\
\text { OR }(95 \% \mathrm{CI})\end{array}$ & $\mathrm{p}^{\mathrm{b}}$ & $\begin{array}{c}\text { TM/MM vs TT } \\
\text { (dominant) } \\
\text { OR }(95 \% \mathrm{CI})\end{array}$ & $\mathrm{p}^{\mathrm{b}}$ \\
\hline Total & 36 & $1.06(0.97-1.16) \mathrm{c}$ & 0.003 & $1.06(1.01-1.12)^{*}$ & 0.052 & $0.93(0.87-1.01)^{\mathrm{c}}$ & 0.008 & $1.02(0.96-1.07) \mathrm{c}$ & 0.017 \\
\hline \multicolumn{10}{|l|}{ Ethnicity } \\
\hline Asian & 4 & $1.66(0.99-2.80)$ & 0.731 & $1.49(0.87-2.54)$ & 0.579 & $0.62(0.38-1.02)$ & 0.720 & $1.34(1.09-1.64)^{*}$ & 0.819 \\
\hline African & 2 & $0.77(0.50-1.19)$ & 0.381 & $0.82(0.52-1.28)$ & 0.217 & $1.27(0.83-1.95)$ & 0.312 & $0.92(0.75-1.13)$ & 0.465 \\
\hline Caucasian & 23 & $1.03(0.94-1.14)^{\mathrm{c}}$ & 0.004 & $1.04(0.98-1.11)$ & 0.065 & $0.96(0.88-1.05)^{\mathrm{c}}$ & 0.010 & $1.02(0.98-1.07)$ & 0.088 \\
\hline Mixed & 7 & $1.13(0.98-1.30)$ & 0.073 & $1.18(1.02-1.35)^{*}$ & 0.215 & $0.87(0.76-0.99)^{*}$ & 0.137 & $1.00(0.85-1.19)^{\mathrm{c}}$ & 0.028 \\
\hline \multicolumn{10}{|l|}{ Study design } \\
\hline $\mathrm{PB}$ & 16 & $1.10(1.03-1.18)^{*}$ & 0.246 & $1.10(1.03-1.18)^{*}$ & 0.520 & $0.91(0.86-0.97)^{*}$ & 0.340 & $1.02(0.98-1.07)$ & 0.223 \\
\hline HB & 20 & $1.08(0.90-1.29)^{\mathrm{c}}$ & 0.002 & $1.06(0.91-1.24)^{\mathrm{c}}$ & 0.028 & $0.92(0.79-1.07)^{\mathrm{c}}$ & 0.006 & $1.06(0.96-1.18)^{\mathrm{c}}$ & 0.010 \\
\hline
\end{tabular}

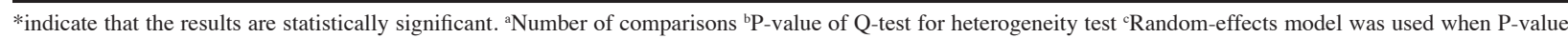
for heterogeneity test $<0.05$; otherwise, fix-effects model was used

vs MM: $\left.\mathrm{OR}=0.91,95 \% \mathrm{CI}=0.86-0.97, P_{\text {heterogeneity }}=0.340\right)$.

Sensitive analysis

Selective bias among the control group was evaluated by the HWE using the chi-square test. Significant deviation from HWE was detected in the five studies[24]. After the exclusion of these studies, the result of XRCC3 $\mathrm{T} 241 \mathrm{M}$ was practically unchanged in the overall analysis, given that the pooled ORs were as follows:1.06 (0.961.17) for homozygote comparison, 1.08 (1.00-1.17) for hetero -zygote comparison, 0.93 (0.86-1.02) for the recessive model and $1.02(0.98-1.06)$ for the dominant model. Additionally, a single study involved in the metaanalysis was deleted each time to reflect the influence of the individual data set to the pooled ORs, and the corresponding pooled ORs were not materially altered, 


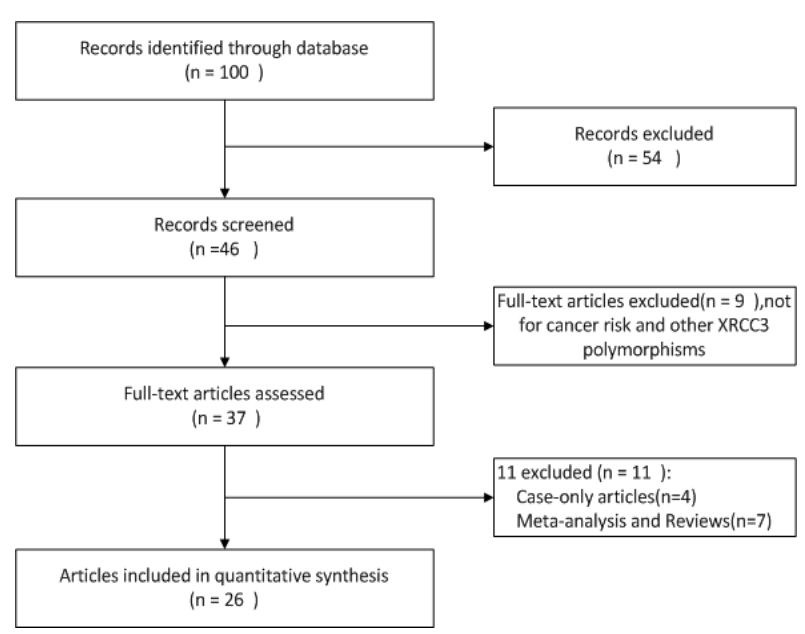

Figure 1. Study Flow Chart Explaining the Selection of the 26 Eligible Articles

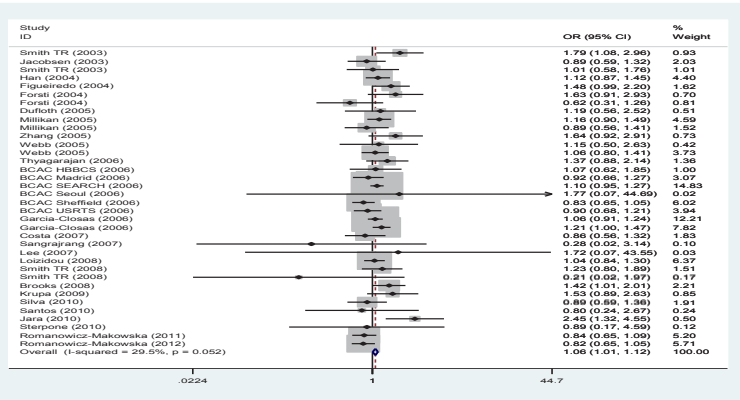

Figure 2. Forest plot of XRCC3 T241M Polymorphism And Breast Cancer when All the Eligible Studies were Pooled Into the Meta-Analysis (heterozygote comparison:MM vs TM)

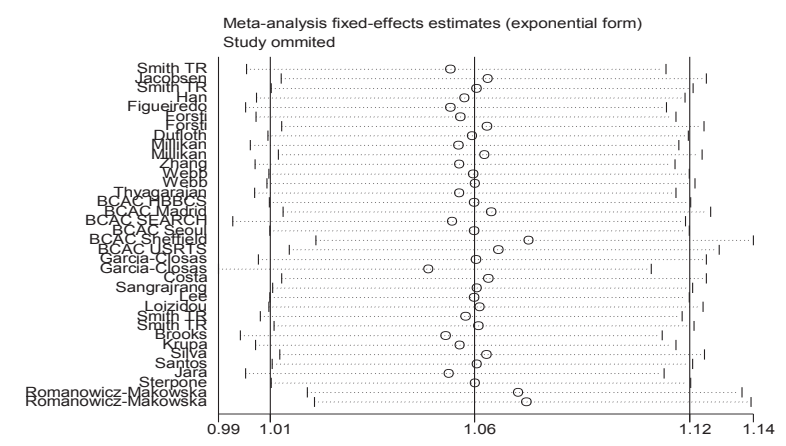

Figure 3. Sensitivity Analysis on the Association T241M Polymorphism and Breast between the XRCC3 Cancer (Heterozygote Comparison: MM vs TM). No statistically different results were obtained by excluding every single study in sequence

indicating that our results were stable and credible (Figure 3).

\section{Publication bias}

Both Begg's funnel plot and Egger's test were used to assess the publication bias of literatures. No significant publication bias was observed ( $p=0.054$ for homozygote comparison, $p=0.724$ for heterozygote comparison, $p=0.724$ for the dominant model, $p=0.621$ for the recessive model). Figure 4 lists the funnel plot in heterozygote comparison.

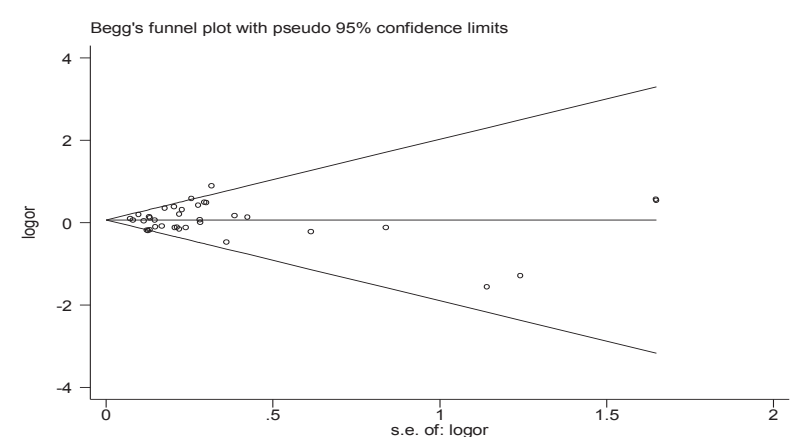

Figure 4. Funnel Plot of Heterozygote Comparison (MM vs TM). Funnel plot of all 36 eligible studies ( $p=0.595$, Egger's test $p=0.724$ )

\section{Discussion}

Many epidemiological studies have reported the role of XRCC3 T241M (rs861539) with breast cancer risk, but the results remained controversial. Some original studies thought that the polymorphism was associated with elevated breast cancer risk, but others had different opinions. In order to resolve this conflict, we performed the updated meta-analysis of 36 eligible studies involving 23,812 cases and 25, 349 controls to derive a more precise estimation of the association between XRCC3 T241M polymorphism and breast cancer risk.

When all eligible studies were pooled into the meta analysis of XRCC3 T241M polymorphism, significantly increased breast cancer risk was observed in heterozygote comparison $(\mathrm{OR}=1.06,95 \% \mathrm{CI}=1.01-1.12)$ (Figure 2). No significant associations were found in other models (homozygote comparison: $\mathrm{OR}=1.06,95 \% \mathrm{CI}=0.97-1.16$; recessive model:OR=0.93, 95\% CI=0.87-1.01; dominant model: $\mathrm{OR}=1.02,95 \% \mathrm{CI}=0.96-1.07)$. However, there was significant heterogeneity between studies. Hence, we further performed subgroup analysis by ethnicity and source of controls. In the stratified analysis of ethnicity, we found significantly increased risks among Asians (TM/MM vs TT: $\mathrm{OR}=1.34,95 \% \mathrm{CI}=1.09-1.64)$ and Mixed ethnicities (MM vs TM: OR=1.18, 95\%CI=1.021.35; TT/TM vs MM: OR=0.87, 95\% CI=0.76-0.99). More importantly, the results of our meta-analysis are in accordance with those reported by Lee et al. (Lee et al., 2007) concerning Asian women. Lee et al. found the $\mathrm{TM} / \mathrm{MM}$ was more strongly associated with breast cancer compared to TT in Asian women. However, the results of Economopoulos et al. (Economopoulos and Sergentanis, 2010)were inconsistent. Economopoulos et al. found the XRCC3 Thr241Met M allele may be associated with elevated breast cancer risk in non-Chinese subjects. It should be considered that the apparent inconsistency may underlie differences in lifestyle and disease prevalence as well as possible limitations due to the small number of studies.At any case, the association between T241M and breast cancer risk in Asian subject essentially remains an open field, as the number of studies $(n=4)$ is smaller than that needed for the achievement of robust conclusions (Higgins and Green, 2008).

We also examined the association of the XRCC3 $\mathrm{T} 241 \mathrm{M}$ polymorphism and breast cancer risk according to source of controls (Table 2). For the population-based 
studies, the XRCC3 T241M polymorphism was associated with breast cancer, given that the pooled ORs were as follows: 1.10 (1.03-1.18) for homozygote comparison, $1.10(1.03-1.18)$ for heterozygote comparison, $0.91(0.86-$ $0.97)$ for the recessive model.

For the hospital-based studies, no significant risks were found (Table 2). However, significantly between-studies heterogeneity was observed in the hospital-based controls for breast cancer. The reason may be that such controls in these hospital-based studies may contain certain benign diseases which are prone to develop malignancy and may not be very representative of the general population.

In addition, some limitations of this study should be considered in our meta-analysis. First, the case subjects were simply defined as breast cancer patients, including both familial and triple-negative breast cancer patients in some of the studies. Second, lack of available information impeded a more precise evaluation with the adjustment by age, status, smoking, alcohol consumption, and menopausal status, etc .Third, it was difficult to get all articles published in various language. We only the studies published in English and Chinese were involved. Finally, this meta-analysis was based on unadjusted OR estimates. Therefore, further and larger studies regarding the association among the XRCC3 T241M polymorphism, XRCC3 T241M levels and the factors mentioned above will be urgently needed.

In conclusion, this meta-analysis supports that $\mathrm{T} 241 \mathrm{M}$ polymorphism show a weakly increased breast cancer risk. A study with the larger sample size is needed to further evaluated gene-gene and gene-environment interactions on XRCC3 T241M polymorphism and breast cancer risk.

\section{Acknowledgements}

The present study is supported by National Natural Science Foundation of China (81272470) provided to Jin-hai Tang and Jian-hua Zhao.

\section{References}

Bewick M A, Conlon M S, Lafrenie R M (2006). Polymorphisms in XRCC1, XRCC3, and CCND1 and survival after treatment for metastatic breast cancer. J Clin Oncol, 24, 5645-51.

Breast Cancer Association C (2006). Commonly studied singlenucleotide polymorphisms and breast cancer: results from the Breast Cancer Association Consortium. J Natl Cancer Inst, 98, 1382-96.

Brooks J, Shore RE, Zeleniuch-Jacquotte A, et al (2008). Polymorphisms in RAD51, XRCC2, and XRCC3 are not related to breast cancer risk. Cancer Epidemiol Biomarkers Prev, 17, 1016-9.

Costa S, Pinto D, Pereira D, et al (2007). DNA repair polymorphisms might contribute differentially on familial and sporadic breast cancer susceptibility: a study on a Portuguese population. Breast Cancer Res Treat, 103, 209-17.

DerSimonian R, Laird N (1986). Meta-analysis in clinical trials. Control Clin Trials, 7, 177-88.

Dufloth R M, Costa S, Schmitt F, et al (2005). DNA repair gene polymorphisms and susceptibility to familial breast cancer in a group of patients from Campinas, Brazil. Genet Mol Res, 4, 771-82.
Dufloth RM,Arruda A, Heinrich JK, et al (2008). The investigation of DNA repair polymorphisms with histopathological characteristics and hormone receptors in a group of Brazilian women with breast cancer. Genet Mol Res, 7, 574-82.

Economopoulos KP, Sergentanis TN (2010). XRCC3 Thr241Met polymorphism and breast cancer risk: a meta-analysis. Breast Cancer Res Treat, 121, 439-43.

Egger M, Davey Smith G, Schneider M, et al (1997). Bias in meta-analysis detected by a simple, graphical test. $B M J$, 315, 629-34.

Falvo E, Strigari L, Citro G, et al (2011). Dose and polymorphic genes xrcc1, xrcc3, gst play a role in the risk of articledeveloping erythema in breast cancer patients following single shot partial breast irradiation after conservative surgery. BMC Cancer, 11, 291.

Figueiredo JC, Knight JA, Briollais L, et al (2004). Polymorphisms XRCC1-R399Q and XRCC3-T241M and the risk of breast cancer at the Ontario site of the Breast Cancer Family Registry. Cancer Epidemiol Biomarkers Prev, 13, 583-91.

Forsti A, Angelini S, Festa F, et al (2004). Single nucleotide polymorphisms in breast cancer. Oncol Rep, 11, 917-22.

Gage M, Wattendorf D, Henry L R (2012). Translational advances regarding hereditary breast cancer syndromes. $J$ Surg Oncol, 105, 444-51.

Garcia-Closas M, Egan KM, Newcomb PA, et al (2006). Polymorphisms in DNA double-strand break repair genes and risk of breast cancer: two population-based studies in USA and Poland, and meta-analyses. Hum Genet, 119, 376-88.

Goode EL, Ulrich CM, Potter JD (2002). Polymorphisms in DNA repair genes and associations with cancer risk. Cancer Epidemiol Biomarkers Prev, 11, 1513-30.

Han J, Hankinson S E, Ranu H, et al (2004). Polymorphisms in DNA double-strand break repair genes and breast cancer risk in the Nurses' Health Study. Carcinogenesis, 25, 189-95.

Han S, Zhang H T, Wang Z, et al (2006). DNA repair gene XRCC3 polymorphisms and cancer risk: a meta-analysis of 48 case-control studies. Eur J Hum Genet, 14, 1136-44.

He X F, Wei W, Su J, et al (2012). Association between the XRCC 3 polymorphisms and breast cancer risk: metaanalysis based on case-control studies. Mol Biol Rep, 39, 5125-34.

He X F, Wei W, Li J L, et al (2013). Association between the XRCC3 T241M polymorphism and risk of cancer: evidence from 157 case-control studies. Gene, 523, 10-9.

Higgins J, Green S (2008). Cochrane handbook for systematic reviews of interventions version 5.0.1. The Cochrane Collaboration, Oxford.

Jacobsen N R, Nexo B A, Olsen A, et al (2003). No association between the DNA repair gene XRCC3 T241M polymorphism and risk of skin cancer and breast cancer. Cancer Epidemiol Biomarkers Prev, 12, 584-5.

Jara L, Dubois K, Gaete D, et al (2010). Variants in DNA doublestrand break repair genes and risk of familial breast cancer in a South American population. Breast Cancer Res Treat, 122, 813-22.

Jemal A, Bray F, Center MM, et al (2011). Global cancer statistics. CA Cancer J Clin, 61, 69-90.

Krupa R, Synowiec E, Pawlowska E, et al (2009). Polymorphism of the homologous recombination repair genes RAD51 and XRCC3 in breast cancer. Exp Mol Pathol, 87, 32-5.

Lee SA, Lee KM, Park SK, et al (2007). Genetic polymorphism of XRCC3 Thr241Met and breast cancer risk: case-control study in Korean women and meta-analysis of 12 studies. Breast Cancer Res Treat, 103, 71-6.

Lengauer C, Kinzler KW, Vogelstein B (1998). Genetic instabilities in human cancers. Nature, 396, 643-9. 
Chang-Fei Mao et al

Loizidou MA, Michael T, Neuhausen SL, et al (2008). Genetic polymorphisms in the DNA repair genes XRCC1, XRCC2 and XRCC3 and risk of breast cancer in Cyprus. Breast Cancer Res Treat, 112, 575-9.

Mantel N, Haenszel W (1959). Statistical aspects of the analysis of data from retrospective studies of disease. J Natl Cancer Inst, 22, 719-48.

Millikan RC, Player JS, Decotret AR, et al (2005). Polymorphisms in DNA repair genes, medical exposure to ionizing radiation, and breast cancer risk. Cancer Epidemiol Biomarkers Prev, 14, 2326-34.

Popanda O, Tan XL, Ambrosone CB, et al (2006). Genetic polymorphisms in the DNA double-strand break repair genes XRCC3, XRCC2, and NBS1 are not associated with acute side effects of radiotherapy in breast cancer patients. Cancer Epidemiol Biomarkers Prev, 15, 1048-50.

Qin L Y, Chen X, Li P, et al (2013). Association between the XRCC3 Thr241Met polymorphism and cervical cancer risk: a meta-analysis. Asian Pac J Cancer Prev, 14, 6703-7.

Romanowicz-Makowska H, Smolarz B, Zadrozny M, et al (2011). Single nucleotide polymorphisms in the homologous recombination repair genes and breast cancer risk in Polish women. Tohoku J Exp Med, 224, 201-8.

Romanowicz-Makowska H, Brys M, Forma E, et al (2012). Single nucleotide polymorphism (SNP) Thr241Met in the XRCC 3 gene and breast cancer risk in Polish women. Pol $J$ Pathol, 63, 121-5.

Sangrajrang S, Schmezer P, Burkholder I, et al (2007). The XRCC3 Thr241Met polymorphism and breast cancer risk: a case-control study in a Thai population. Biomarkers, 12, 523-32.

Santos RA, Teixeira AC, Mayorano MB, et al (2010). DNA repair genes XRCC1 and XRCC3 polymorphisms and their relationship with the level of micronuclei in breast cancer patients. Genet Mol Biol, 33, 637-40.

Silva SN, Tomar M, Paulo C, et al (2010). Breast cancer risk and common single nucleotide polymorphisms in homologous recombination DNA repair pathway genes XRCC2, XRCC3, NBS1 and RAD51. Cancer Epidemiol, 34, 85-92.

Smith TR, Miller MS, Lohman K, et al (2003). Polymorphisms of XRCC1 and XRCC3 genes and susceptibility to breast cancer. Cancer Lett, 190, 183-90.

Smith TR, Levine EA, Freimanis R I, et al (2008). Polygenic model of DNA repair genetic polymorphisms in human breast cancer risk. Carcinogenesis, 29, 2132-8.

Smith T R, Levine EA, Perrier N D, et al (2003). DNA-repair genetic polymorphisms and breast cancer risk. Cancer Epidemiol Biomarkers Prev, 12, 1200-4.

Sterpone S, Mastellone V, Padua L, et al (2010). Singlenucleotide polymorphisms in BER and HRR genes, XRCC1 haplotypes and breast cancer risk in Caucasian women. $J$ Cancer Res Clin Oncol, 136, 631-6.

Thyagarajan B, Anderson KE, Folsom AR, et al (2006). No association between XRCC1 and XRCC 3 gene polymorphisms and breast cancer risk: Iowa Women's Health Study. Cancer Detect Prev, 30, 313-21.

Ward JF (1988). DNA damage produced by ionizing radiation in mammalian cells: identities, mechanisms of formation, and reparability. Prog Nucleic Acid Res Mol Biol, 35, 95-125.

Webb PM, Hopper JL, Newman B, et al (2005). Double-strand break repair gene polymorphisms and risk of breast or ovarian cancer. Cancer Epidemiol Biomarkers Prev, 14, 319-23.

Yin QH, Liu C, Li L, et al (2012). Association between the XRCC3 T241M polymorphism and head and neck cancer susceptibility: a meta-analysis of case-control studies. Asian Pac J Cancer Prev, 13, 5201-5.
Zhang L, Zhang Z, Yan W (2005). Single nucleotide polymorphisms for DNA repair genes in breast cancer patients. Clin Chim Acta, 359, 150-5. 